UDC 316.342

LBC 60.524-60.56

\title{
INTERACTION OF COMMUNITY AND FAMILY PATTERNS OF LIFE IN SOUTHERN VILLAGES (BASED ON RESEARCH MATERIALS OF 2018) ${ }^{1}$
}

\author{
Ludmila V. Namrueva \\ Kalmyk Scientific Center of the Russian Academy of Sciences, Elista, Russian Federation
}

\begin{abstract}
There is a combination of two and more household practices - collective and family ones in a modern village. The author of the article describes the changes of collective farms in the South of Russia in the early $21^{\text {st }}$ century. During the transformations of the 1990s, the collective way of life supported the village, rural society in the struggle for survival, thereby preventing social cataclysms. Former Soviet state farms and collective farms turned into agricultural organizations (agricultural associations) or gradually disappeared. The author analyzes the fate of collective farms in such South Russian regions as the Republic of Kalmykia, Astrakhan and Volgograd regions, Stavropol region, which are large agricultural producers. Collective farms in these regions could not avoid the disastrous consequences of the agrarian reforms of the 1990s, which resulted in a huge number of "abandoned" villages left without village-forming enterprises. The researcher analyzes some results of sociological research conducted in summer-autumn 2018 in the studied South Russian regions. 400 rural residents, 100 people in each subject were interviewed. The results of the study demonstrate that the way of private farms (36\%) is common in all analyzed regions. This is followed by PFEs (peasant farm enterprises) $(15 \%)$, agricultural enterprises $(9 \%)$. The number of agricultural associations and the number of their employees have significantly decreased. Small farms of the population are the basis of the agricultural society of the regions under consideration. The author defines three urgent problems of four regions. They are the following: a decent wage, a good leader suggesting the way out of a difficult situation, consolidation of young people in the countryside. The analysis shows that interaction between collective and family patterns of life is gradually dimming. The owners of private farms are becoming more autonomous, their dependence on the farm is gradually disappearing.
\end{abstract}

Key words: collective pattern of life, agricultural organizations, private farms, rural population, South of Russia.

УДК 316.342

ББК 60.524-60.56

\section{ВЗАИМОДЕЙСТВИЕ КОЛЛЕКТИВНОГО И СЕМЕЙНОГО УКЛАДОВ В ЮЖНОРОССИЙСКИХ СЕЛАХ (ПО МАТЕРИАЛАМ ИССЛЕДОВАНИЯ 2018 г.) ${ }^{1}$}

\footnotetext{
Людмила Васильевна Намруева

Аннотация. В современной деревне встречается сочетание двух хозяйственных укладов - коллективного и семейного. В статье описаны изменения коллективных хозяйств на Юге России в начале XXI столетия. В ходе преобразований 1990-х гг. коллективный уклад поддержал село, сельский социум в борьбе за выживание, тем самым предотвратив социальные катаклизмы. Бывшие советские совхозы и колхозы превращались в сельскохозяйственные организации (СХO) или постепенно исчезали. Автор статьи анализирует судьбу коллективных хозяйств в таких южнороссийских регионах, как Республика Калмыкия, Астраханская и Волгог-
} 
радская области, Ставропольский край, которые являются крупными аграрными производителями. Коллективные хозяйства этих регионов не смогли избежать катастрофических последствий аграрных реформ 1990-х гг., в результате которых появилось огромное количество «брошенных» сел, оставшихся без селообразующих предприятий. Анализируются отдельные результаты социологического исследования, проведенного летом - осенью 2018 г. в рассматриваемых южнороссийских регионах. Опрошено 400 сельских жителей, 100 человек в каждом субъекте. Результаты показывают, что уклад личных подсобных хозяйств (36 \%) распространен во всех анализируемых регионах. Далее следуют КФХ (15\%), сельскохозяйственные предприятия (9\%). Значительно сократились количество СХО и численность занятых в них. Малые хозяйства населения являются основой сельского социума рассматриваемых регионов. Определена тройка актуальных проблем четырех регионов. Это достойная оплата труда, хороший руководитель, знающий выход из сложного положения, закрепление молодежи на селе. Анализ показал, что постепенно стирается взаимосвязь между коллективным и семейным укладами. Владельцы личных подсобных хозяйств становятся более автономными, их зависимость от сельхозпредприятия постепенно исчезает.

Ключевые слова: коллективный уклад, сельскохозяйственные организации, личные подсобные хозяйства, сельское население, Юг России.

\section{Введение}

В 2000-2010-е гг. активно стали изучать сельские территории, их экономический и сельскохозяйственный потенциал, что связано с введением экономических санкций западных государств против России, необходимостью анализа трудовых ресурсов для реализации программ по продовольственной независимости страны. Южный федеральный округ (ЮФО), успешно решая задачи импортозамещения, играет важную роль в обеспечении продовольственной безопасности страны. Исследуемые крупные аграрные регионы (Республика Калмыкия, Астраханская область, Волгоградская область, Ставропольский край) успешно занимаются растениеводством, кормопроизводством, животноводством. В 1990-е гг. поголовье крупного рогатого скота на юге страны сократилось, как и по всей стране, и в нулевые годы оно продолжало сокращаться.

За постсоветский период в аграрной отрасли значительно сократилось число крупных сельхозпроизводителей, что, в свою очередь, привело к существенному снижению валовой продукции, производимой в сельхозорганизациях ЮФО. Актуальность исследования продиктована необходимостью всестороннего анализа взаимодействия хозяйственных укладов в сельской местности, чтобы своевременно разрабатывать рекомендации для принятия управленческих решений на различных уровнях власти, адекватных вызовам, угрожающим продовольственной безопасности страны.

\section{Исследование вопроса}

Исследованию социально-экономических последствий российских аграрных реформ 1990-х гг., процессов исчезновения, сохранения и возрождения хозяйственной деятельности сельского населения, стратегий адаптации сельского социума и сельскохозяйственных предприятий к изменяющимся условиям посвящены работы Е. Бочаровой, П. Великого [Великий, Бочарова 2014], 3. Калугиной [Калугина 2015], Т. Нефедовой [Нефедова, $2013 ; 2014 ; 2018$ ], О. Нечипоренко [Нечипоренко 2011], Э. Сагдиевой [Сагдиева 2017], Ж. Тощенко [Тощенко 2017], О. Фадеевой [Фадеева 2015], Н. Шагайды [Шагайда 2018] и др., которые в своих работах анализируют причинно-следственные связи исчезновения старых и создания новых форм хозяйственной организации в сельских поселениях, факторы, позволяющие селу устоять и развиваться в условиях постоянных изменений. Следует отметить, что до сих пор отсутствует единый подход в описании трансформации форм организации хозяйственной жизни в условиях рыночной экономики современной России.

Согласно разделяемому нами мнению Т.Г. Нефедовой, «постсоветские годы характеризуются двумя важными для сельского хозяйства и сельской местности тенденциями. Первая связана с усилением в новых рыночных условиях дифференциации бывших советских предприятий, что привело к закрытию недееспособных предприятий, долгие годы сидящих на больших дотациях, и стимулиро- 
вало более эффективные, правда, часто с изменением специализации. Это усилило поляризацию сельского пространства: сельское хозяйство “сдвинулось” в районы, где производство более эффективно и обеспечено природными и трудовыми ресурсами. Вторая тенденция связана с модернизацией выживших предприятий и появлением агрохолдингов, формирующихся не “снизу” от производителей, а преимущественно “сверху” - от пищевых предприятий, финансовых, государственных структур и т. п.» [Нефедова 2018, 117-118]. В нашем анализе остановимся на рассмотрении первой тенденции.

Автор статьи также использует опыт социолога из Новосибирска, О.П. Фадеевой, которая разработала свою концепцию формирования и трансформации сельских хозяйственных укладов, делая акцент на роли последних в самоорганизации сельских сообществ в период постсоветских аграрных реформ. К признакам крупных коллективных хозяйств она относит «неделимую собственность на средства производства, несменяемый профиль производства, избыток рабочей силы, низкий уровень конкурентоспособности и неэффективный в рыночных условиях менеджмент» [Фадеева 2015, 100]. По мнению этого исследователя, «данный хозяйственный уклад существовал благодаря специфической аграрной политике федеральных и региональных властей, сдерживающей массовое банкротство и ликвидацию финансово несостоятельных сельхозпредприятий» [Фадеева 2015, 100]. Полностью разделяем утверждение О.П. Фадеевой о том, что за 15 лет нового столетия роль данного уклада значительно снизилась, хотя его отдельные элементы существуют в функционирующих сельскохозяйственных организациях (CXO). Особенно это касается тех регионов, где «власти искусственно поддерживают существование убыточных предприятий, чтобы сохранить сельские поселения и реализовать планы по перепрофилированию и диверсификации сельской экономики» [Фадеева 2015, 117].

\section{Трансформация коллективного уклада}

В деревне традиционно бытовали два хозяйственных уклада. В 1950-1960-е гг. разви- вались коллективный (колхозы и совхозы) и частный, семейный (личные подсобные хозяйства (ЛПХ)) хозяйственные уклады. Следует заметить, что многие исследователи считают «ЛПХ более прогрессивным в силу хозяйственной инициативы сельских жителей и возможности роста эффективности аграрной отрасли» (цит. по: [Краснов 2016, 48]).

В 1980-е и в нач. 1990-х гг. указанные уклады тесно взаимодействовали: совхозы передавали в семейные подсобные хозяйства отдельные процессы производственной деятельности (выращивание молодняка, уход за животными и т. д.), обеспечивая их необходимыми кормами, ветеринарной помощью. Работники могли получать продукты «под зарплату» в магазинах, где сельхозпредприятия реализовывали продукцию, произведенную в пекарнях, цехах по изготовлению мясных полуфабрикатов и т. д. В этих условиях семейное хозяйство, ориентированное на рынок, было наиболее эффективным. И наоборот, если ЛПХ слабо ориентировано на рынок и связь с крупным производством, то оно наименее эффективно. Совершенно прав М.М. Краснов, утверждая, что «в условиях советской распределительной экономики, запретов и ограничений на предпринимательскую деятельность был невозможен рост семейных подворий, их превращение в товарные» [Краснов 2016, 48].

В результате аграрной реформы 1990-х гг. сложилось многообразие сельских укладов, основанных на различных способах хозяйствования и разном образе жизни. Хозяйственноукладная структура сельских территорий кардинально изменилась. Эти преобразования необходимо исследовать с целью предупреждения таких нежелательных последствий, как катастрофическое исчезновение деревень, господство в них конкретного хозяйственного уклада, вытеснившего остальные. Согласно разделяемому нами мнению ученых, «равноправное существование хозяйственных укладов и их рациональное взаимодействие играет позитивную роль в обеспечении устойчивого развития сельских территорий и в поддержании уровня жизни сельского населения» [Краснов 2016, 51]. Одна из задач нашего исследования заключается в выявлении взаимодействия различных хозяйственных укладов в современной сельской местности, вариан- 
тов сочетания рыночной конкуренции и сотрудничества укладов.

Далее проанализируем результаты социологического исследования, проведенного в осенью 2018 г. в Республике Калмыкия, Астраханской и Волгоградской областях, Ставропольском крае. Выборочная совокупность составила 400 сельских жителей, по 100 в каждом регионе, поровну мужчин и женщин.

Один из вопросов анализируемого анкетного опроса позволил выяснить, занимаются ли наши респонденты сельским хозяйством. Из ответов явствует, что лишь небольшая часть (от 5 до 7 \%) опрошенных в Калмыкии, Астраханской и Волгоградской областях работают в сельскохозяйственном предприятии. Это свидетельствует о том, что многие сельские поселения этих южнороссийских регионов существуют без селообразующего предприятия, которые либо ликвидированы, либо стали малыми с небольшим числом работников. В Ставропольском крае каждый пятый опрошенный оказался работником СХО (это самый высокий показатель по этому ответу). Статистические данные показывают, что по количеству крупных и средних сельхозпредприятий Старополье значительно опережает суммированное количество этих предприятий в трех других регионах. В Ставропольском крае, за исключением северовосточных районов, граничащих с Калмыкией, имеются благоприятные природно-климатические условия для развития сельскохозяйственного производства. На таких территориях эффективней развиваются крупные сельхозпредприятия.

От $6 \%$ респондентов-астраханцев до $11 \%$ респондентов - жителей трех других регионов отметили, что занимались сельскохозяйственной деятельностью до развала СССР. Этот результат показывает опосредованным образом, каковы масштабы сокращения крупных и средних сельхозпредприятий.

В среднем $8 \%$ респондентов заняты в своем крестьянском фермерском хозяйстве. Из ответов анкетирования следует, что больше всего фермеров в Ставропольском крае (16\%), а меньше всего - в Калмыкии (4\%). Работает по найму у фермера небольшая доля из всей выборочной совокупности (7 \%). Фер- меры не оправдали возложенных на них надежд, не заменили колхозы и совхозы своей деятельностью. Постепенно слабые фермерские хозяйства разорялись, набирали силу крупные КФХ, владельцы которых смогли объединить ресурсы мелких, неэффективно работавших крестьянских хозяйств.

В целом более трети (36 \%) опрошенных ведут (помогают вести) личное подсобное хозяйство. Из результатов видно, что данный уклад более распространен в Волгоградской области (46\%) и Астраханской области (44 \%), нежели чем в Калмыкии (26 \%) и Ставрополье (2\%).

Более четверти всей выборки (29\%) отметили, что «члены моей семьи не занимаются сельскохозяйственными работами». Это косвенно показывает, что на селе получили свое распространение и другие виды деятельности, не связанные с аграрной отраслью. Более всего этот вариант выбран астраханскими (41 \%) и калмыцкими (39\%) респондентами.

Полученные данные позволяют нам понять, какой из укладов распространен в исследуемых территориях. Опережает уклад личных подсобных хозяйств (36 \%), он лидирует во всех анализируемых регионах. Далее следуют КФХ (15\% в сумме двух ответов), замыкают тройку сельскохозяйственные предприятия (9\%). Таким образом, мелкие хозяйства населения являются основой всего сельского социума. Считаем, что село живет, пока функционируют личные хозяйства [Намруева 2017, 88].

С помощью анкетирования выясняли мнение селян о том, в чем село и сельское хозяйство нуждаются в первую очередь. По всем регионам можно определить список приоритетных задач, ранжирование их несколько различается. Первая тройка актуальных проблем четырех регионов, по мнению респондентов, общая: это достойная оплата труда, хороший руководитель, знающий выход из сложного положения, закрепление молодежи на селе (см. табл. 1).

Академик А.И. Алтухов отмечает, что уровень оплаты труда работников сельскохозяйственной отрасли составляет лишь $57 \%$ от среднего показателя по экономике. Почти у $40 \%$ работающих в сельскохозяйственных 


\section{СОЦИОЛОГИЯ И СОЦИАЛЬНЫЕ ТЕХНОЛОГИИ}

организациях зарплата ниже прожиточного минимума трудоспособного населения. Следует отметить, что у сельских жителей доля расходов на покупку пищевых продуктов в потребительских расходах домохозяйств значительно выше, чем у городских жителей [Алтухов 2018]. Специалисты отмечают, что вследствие низкой доходности сельскохозяйственного труда $17 \%$ селян находятся за чертой бедности (в городах - 9,2\%). Уровень сельской бедности в 1,7 раза превосходит допустимую 10 \%-ную планку, по международным оценкам. Заработная плата в аграрном секторе составляет почти 50 \% по отношению к среднероссийскому уровню, не обеспечивая ни воспроизводства рабочей силы, ни стимулирования труда [Бондаренко 2016, 76]. Безусловно, такая оплата труда сельских жителей не может устраивать.

Эффективный менеджмент способен изменить ситуацию на селе. К сожалению, аграрная отрасль испытывает острый недостаток в руководителях, способных найти нестандартные инновационные решения, чтобы вывести аграрное предприятие на новый уровень развития. Согласно разделяемому нами мнению П.П. Великого, Е.В. Бочаровой, «менеджмент крупхозов и фермеры ограничиваются заботой о небольшой доле сельских сообществ, которой посчастливилось получить работу, и они входят в производственный персонал. Современный крупхоз очень мал и по масштабам производства, и по числу занятых - не более вчерашней колхозной бригады или отделения совхоза. Люди, оставшиеся вне вновь созданной системы (напомним, 8 из
10 млн ранее имевших рабочие места), должны были позаботиться о себе сами, находить каналы источников выживания» [Великий, Бочарова 2014, 31].

Жители малых и отдаленных сел, трудившиеся на фермах и других подразделениях $\mathrm{CXO}$, в результате банкротства предприятия лишились не только работы, но и порой единственного источника доходов. Единственным выходом для многих стала миграция за пределы родного села в поисках средств существования. Середина 1990-х и 2000-е гг. явились периодом активных социальных перемещений для большей части сельского населения, разуверившегося в том, что жизнь вернется на прежние устоявшиеся позиции.

Для анализируемых регионов, как и для всей страны, острой социальной проблемой является безвозвратная миграция молодых людей за пределы сельских территорий. После получения образования многие из них не видят перспектив трудоустройства в сельской местности. Однонаправленный процесс миграции в города, к сожалению, нарастает, а число нетрудоустроенной в селе молодежи увеличивается ежегодно, ослабляя профессиональный потенциал сельской экономики. Потому эта проблема нашими респондентами названа одной из злободневных.

Неблагоприятная обстановка в сельском социуме усиливает миграционное поведение жителей. Общая картина ответов на закрытый вопрос о связи опрошенных с сельской местностью такова: большая часть респондентов (61 \%) положительно ответила на этот

Таблица 1

Распределение ответов на вопрос «В чем село и сельское хозяйство района нуждаются в первую очередь?» (\%)

\begin{tabular}{|c|c|c|c|c|c|c|c|c|}
\hline \multirow{3}{*}{$\begin{array}{l}\text { Варианты } \\
\text { ответа }\end{array}$} & \multicolumn{8}{|c|}{ Регионы } \\
\hline & \multicolumn{2}{|c|}{ PK } & \multicolumn{2}{|c|}{ Астраханская обл. } & \multicolumn{2}{|c|}{ Волгоградская обл. } & \multicolumn{2}{|c|}{ Ставропольский край } \\
\hline & Общ. сред. & Ранг & Общ. сред. & Ранг & Общ. сред. & Ранг & Общ. сред. & Ранг \\
\hline В передовых технологиях & 18 & 4 & 6 & 6 & 12 & 5 & 12 & 5 \\
\hline В обновлении техники & 16 & 5 & 10 & 5 & 20 & 4 & 13 & 4 \\
\hline $\begin{array}{l}\text { В закреплении молодежи } \\
\text { на селе }\end{array}$ & 23 & 3 & 16 & 3 & 28 & 1 & 14 & 3 \\
\hline $\begin{array}{l}\text { В хорошем руководителе, } \\
\text { знающем выход из слож- } \\
\text { ного положения }\end{array}$ & 32 & 1 & 20 & 2 & 2 & 2 & 19 & 2 \\
\hline В достойной оплате труда & 31 & 2 & 43 & 1 & 23 & 3 & 48 & 1 \\
\hline $\begin{array}{l}\text { В строительстве доступ- } \\
\text { ного жилья }\end{array}$ & 11 & 6 & 12 & 4 & 5 & 6 & 9 & 6 \\
\hline
\end{tabular}


вопрос, а более трети выборки (39 \%) дали отрицательный ответ (табл. 2). Рассмотрим подробней общие результаты. Четверть опрошенных нашего исследования (25\%) не связывают свою жизнь с сельской местностью, по их мнению, на селе практически нет условий для комфортной жизни. $13 \%$ настроены на отъезд, потому что их дети хотят жить в городе.

Из ответивших положительно $18 \%$ респондентов готовы остаться на селе, так как надеются, что придут руководители, которые смогут наладить эффективное ведение хозяйства; $15 \%$ опрошенных связывают свою жизнь с селом, считая, что только на родной земле можно самореализоваться; $15 \%$ не собираются покидать село, поскольку здесь имеются все возможности для развития; $13 \%$ селян останутся, так как жизнь на селе приближается к городской.

Рассмотрение результатов анкетирования в региональном разрезе позволяет определить, что миграционные устремления в большей степени характерны для жителей Калмыкии (50 \%), далее по этому критерию следуют респонденты из Астраханской области (39\%), Ставропольского края (38 \%), Волгоградской области $(30,5 \%)$. Соответственно, в Волгоградской области наибольшее количество тех респондентов, кто связывает свою дальнейшую жизнь с селом
(72\%). С этим решением в первую очередь связаны надежды на руководителей $(23 \%)$ и реалии, которые предоставляют все возможности для развития селян (21\%). Одинаковый положительный результат (59\%) показали респонденты из Астраханья и Ставрополья. Однако их результаты отличаются между собой. Так, ставропольцы (30\%) в большей степени полагаются на эффективность управленцев, нежели астраханцы (9\%), которые, в свою очередь, замечают, что жизнь в их селе приближается к городской (23\%). Этот вариант отмечен лишь $8 \%$ ставропольцев.

Наименьшее количество положительных ответов (44 \%) дали калмыцкие респонденты. Все вышерассмотренные причины, связывающие с селом, указаны почти равным количеством опрошенных в диапазоне 10-12\%. Можно отметить, что особого фактора, который сдерживал бы респондентов от решения покинуть село, нет. В этой связи считаем, что совершенно прав известный социолог села П.П. Великий, когда замечает, что в трудовой миграции сельчан заключена возможность их территориальной мобильности, надежда (очень слабая) прервать предзаданность убогой, одномерной жизни. Выживание сельских мигрантов построено на самообеспечении и отсутствии интереса к ним рыночной экономики [Великий 2010, 48].

Таблица 2

Распределение ответов на вопрос «Связываете ли Вы свою жизнь с сельской местностью?» $(\%)$

\begin{tabular}{|c|c|c|c|c|c|c|c|c|}
\hline \multirow[t]{3}{*}{ Варианты ответа } & \multicolumn{8}{|c|}{ Регионы } \\
\hline & \multicolumn{2}{|l|}{ PK } & \multicolumn{2}{|c|}{ Астраханская обл. } & \multicolumn{2}{|c|}{ Волгоградская обл. } & \multicolumn{2}{|c|}{ Ставропольский край } \\
\hline & Общ. сред. & Ранг & Общ. сред. & Ранг & Общ. сред. & Ранг & Общ. сред. & Ранг \\
\hline $\begin{array}{l}\text { Конечно, только на род- } \\
\text { ной земле можно само- } \\
\text { реализоваться }\end{array}$ & 11 & 4 & 15 & 3 & 18 & 3 & 15 & 4 \\
\hline $\begin{array}{l}\text { Да, связываю, поскольку } \\
\text { здесь есть все возможно- } \\
\text { сти для развития }\end{array}$ & 10 & 5 & 12 & 4 & 21 & 2 & 6 & 6 \\
\hline $\begin{array}{l}\text { Да, связываю, т.к. жизнь } \\
\text { на селе приближается к } \\
\text { городской }\end{array}$ & 11 & 4 & 23 & 2 & 10 & 5 & 8 & 5 \\
\hline $\begin{array}{l}\text { Возможно, все зависит от } \\
\text { эффективности в ведения } \\
\text { хозяйства }\end{array}$ & 12 & 3 & 9 & 5 & 23 & 1 & 30 & 1 \\
\hline $\begin{array}{l}\text { Нет, на селе практически } \\
\text { нет условий для ком- } \\
\text { фортной жизни }\end{array}$ & 37 & 1 & 30 & 1 & 18 & 4 & 18 & 3 \\
\hline $\begin{array}{l}\text { Нет, дети хотят жить в } \\
\text { городе }\end{array}$ & 13 & 2 & 9 & 5 & 12,5 & 5 & 20 & 2 \\
\hline
\end{tabular}




\section{Выводы}

В современном российском селе действуют четыре основных хозяйственных уклада - корпоративный, вышедший из коллективного, имеющий две разновидности - корпоративно-потребительский (СХО, СПК) и корпоративно-предпринимательский (агрохолдинги); семейный, также имеющий два вида семейно-потребительский (ЛПХ) и семейнопредпринимательский (КФХ).

Трансформация коллективного уклада проходила следующим образом. Большинство колхозов и совхозов, став акционерными обществами, распределили паи между работниками хозяйства, пенсионерами и лицами, занятыми в социальной сфере села. Наличие земельных долей сыграло важную роль в развитии аграрных отношений современного села: сформирован рынок сельскохозяйственных земель и организованы новые формы - крестьянско-фермерские хозяйства (КФХ). Исследователи отмечают, что «аренда земель позволяла обходить запрет купли-продажи земель сельскохозяйственного назначения, который действовал до середины 2000-х годов. Владельцы земельных долей, получив право ими распоряжаться, передавали землю тому арендатору, который предлагал выгодные условия по арендной плате, которая чаще всего имела натуральную форму в виде обговоренной части урожая зерновых» [Краснов $2016,48]$, количества молодняка, сельскохозяйственной продукции (мяса, яиц) и отдельных услуг по ведению семейного подворья.

Разделяем мнение Ж.Т. Тощенко о том, что «эффект от реальных преобразований сельского хозяйства оказался незначительным - тон во многом продолжают задавать, как и в советское время, личные подсобные хозяйства и частично сельхозпредприятия, от которых коренного перелома в достижении производительности и эффективности при существующей аграрной политике добиться трудно» [Тощенко 2017, 93].

Проведенный нами анализ свидетельствует о том, что уменьшилась численность работников сельскохозяйственных организаций, лишь от 5 до $7 \%$ респондентов трудоустроены в них. В былые времена рабочие совхоза всегда рассчитывали на помощь с его стороны в поддержке своих подсобных хозяйств.
Ныне, в условиях рынка, они полагаются на свои силы и деловые качества: корма и необходимые услуги приобретают по договорным ценам. Наше исследование показало, что личные подсобные хозяйства, адаптируясь к рыночным условиям, занимают определенную нишу в аграрном секторе и обеспечивают достойный уровень жизни определенной части сельского населения. Как видим, постепенно стирается тесная связь между двумя укладами, коллективным и семейным, вторые становятся более независимыми от предприятия, чем в недалеком прошлом.

\section{ПРИМЕЧАНИЕ}

${ }^{1}$ Статья подготовлена в рамках государственного задания КалмНЦ РАН «Развитие сельских территорий Юга России: комплексный социально-экономический и экологический мониторинг», рег. № НИОКТР АААА-А19-1190111490037-8.

The work was carried out in the framework of the state task of Kalmyk Scientific Center of the Russian Academy of Sciences "Rural Development in Southern Russia: Complex Socio-Economic and Environmental Monitoring", registration no. НИОКТР AAAA-A19-1190111490037-8.

\section{СПИСОК ЛИТЕРАТУРЫ}

Алтухов 2018 - Алтухов А.И. Проблемы развития АПК страны и необходимость их ускоренного решения // Экономика сельского хозяйства России. 2018. № 4. С. 2-14.

Бондаренко 2016 - Бондаренко Л.В. Развитие сельских территорий России: оценки, мнения, ожидания // Социологические исследования. 2016. № 3. С. 76-82.

Великий 2010 - Великий П.П. Неотходничество, или лишние люди современной деревни // Социологические исследования. 2010. № 9. C. $44-49$.

Великий, Бочарова 2014 - Великий П.П., Бочарова E.B. Динамика формирования многоканальности источников выживания сельской семьи // Известия Сарат. ун-та. Новая серия Серия Социология. Политология. 2014. Т. 14, вып. 1. С. 30-37.

Калугина 2015 - Калугина 3.И. Рыночная трансформация аграрного сектора России: Социологический дискурс. Новосибирск: Изд-во ИЭОПП СО РАН, 2015. 
Краснов 2016 - Краснов М.М. Динамика хозяйственных укладов в российском селе // Известия Сарат. ун-та. Новая серия. Серия Социология. Политология. 2016. № 16. С. 47-52.

Намруева 2017 - Намруева Л.В. Современное село Калмыкии: социологический срез. Элиста: КалмНЦРАН, 2017.

Нефедова 2013 - Нефедова Т.Г. Трансформация сельского хозяйства России: мифология и реальность // Мир России. 2013. № 1. С. 29-58.

Нефедова 2014 - Нефедова Т.Г. Агропромышленная концентрация в российских регионах // ЭКО. Всероссийский экономический журнал. 2014. № 4 (478). С. 64-83.

Нефедова 2018 - Нефедова Т.Г. Современное крестьянское хозяйство в сельско-городской среде // Крестьяноведение. 2018. Т. 5, № 1. С. 117-140.

Нечипоренко 2011 - Нечипоренко О.В. Трансформация хозяйственных укладов в сельском социуме: модели и стратегии развития // Beстник НГУ. Серия: Философия. 2011. Т. 9. C. $78-86$

Сагдиева 2017 - Сагдиева Э.А. Сельскохозяйственные предприятия коллективного труда как одна из форм организационно-экономической структуры сельского хозяйства в Республике Татарстан // Островские чтения. 2017. № 1. С. 435-441.

Тощенко 2017 - Тощценко Ж. Т. Что представляет собой современное российское село? // Социологические исследования. 2017. № 12. С. 89-98.

Фадеева 2015 - Фадеева О.П. Сельские сообщества и хозяйственные уклады: от выживания к развитию. Новосибирск: ИЭОПП СО РАН, 2015.

Шагайда 2018 - Шагайда Н.И. Оценка структурных изменений в сельском хозяйстве: методические подходы и планируемые результаты // Крестьяноведение. 2018. Т. 3, № 2. C. $102-126$.

\section{REFERENCES}

Altukhov A.I., 2018. Problems of development of agroindustrial complex of the country and need of their accelerated decision. Economy of agriculture of Russia, no. 4, pp. 2-14.
Bondarenko L.V., 2016. Development of rural territories of Russia: estimates, opinions, expectations. Sociological research, no. 3, pp. 76-82.

Velikiy P.P., 2010. Not seasonal work, or extra people modern village. Sociological research, no. 9, pp. 44-49.

Velikiy P.P., Bocharova E.V., 2014. The Dynamics of formation of multi-channel sources of livelihood of rural families. Izvestiya Sarat. un-ta. New. ser. Ser. Sociology. Political science, vol. 14, no. 1, pp. 30-37.

Kalugina Z.I., 2015. Market transformation of the agricultural sector of Russia: Sociological discourse. Novosibirsk, Publishing house of the Institute.

Krasnov M.M., 2016. Dynamics of economic structures in the Russian village. Izv. Sarat. un-ta. New. ser. Ser. Sociology. Political science, no. 16, pp. 47-52.

Namrueva L.V., 2017. Modern village of Kalmykia: a sociological slice. Elista, KalrnSC RAS.

Nefedova T.G., 2013. Transformation of agriculture in Russia: mythology and reality. World of Russia, no. 1, pp. 29-58.

Nefedova T.G., 2014. Agro-Industrial concentration in Russian regions. ECO. All-Russian economic journal, no. 4 (478), pp. 64-83.

Nefedova T.G., 2018. Modern peasant economy in the rural-urban environment. Peasant Studie, vol. 5, no. 1, pp. 117-140.

Nechiporenko O.V., 2011. Transformation of economic structures in rural society: models and development strategies. Vestnik NSU. Series: Philosophy, vol. 9, pp. 78-86.

Sagdieva E.A., 2017. Agricultural enterprise collective labor as a form of organizational-economic structure of agriculture in the Republic of Tatarstan. Ostrovskie reading, no. 1, pp. 435-441.

Toschenko Zh.T., 2017. What is a modern Russian village. Sociological research, no. 12, pp. 89-98.

Fadeeva O.P., 2015 . Rural communities and economic structures: from survival to development. Novosibirsk, IEOPP SO RAN.

Shagaida N.I., 2018. Assessment of structural changes in agriculture: methodological approaches and planned results. Peasant Studies, vol. 3, no. 2, pp. 102-126. 


\section{СОЦИОЛОГИЯ И СОЦИАЛЬНЫЕ ТЕХНОЛОГИИ}

\section{Information about the Author}

Ludmila V. Namrueva, Candidate of Sciences (Sociology), Associate Professor, Leading Researcher, Department for Complex Monitoring and Information Technologies, Kalmyk Scientific Center of the Russian Academy of Sciences, Ilishkina St., 8, 358000 Elista, Russian Federation, lnamrueva@yandex.ru, https://orcid.org/0000-0001-7805-8710

\section{Информация об авторе}

Людмила Васильевна Намруева, кандидат социологических наук, доцент, ведущий научный сотрудник отдела комплексного мониторинга и информационных технологий, Калмыцкий научный центр РАН, ул. Илишкина, 8, 358000 г. Элиста, Российская Федерация, lnamrueva@yandex.ru, https://orcid.org/0000-0001-7805-8710 